\title{
Role of Specimen Insulation on Densification and Transformation during Microwave Sintering of Silicon Nitride
}

\author{
Mark I. JONES, Maria-Cecilia VALECILLOS and Kiyoshi HIRAO \\ Synergy Materials Research Center, National Institute of Advanced Industrial Science and Technology, \\ 2268-1, Shimo-Shidami, Moriyama-ku, Nagoya-shi 463-8687
}

\section{窒化ケイ素のマイクロ波焼結時の緻密化及び相転移挙動に及ぼす断熱方法の効果}

\author{
Mark I. Jones · Maria-Cecilia Valecillos · 平尾喜代司 \\ 産業技術総合研究所シナジーマテリアル研究センター，463-8687 名古屋市守山区下志段味 2268-1
}

\begin{abstract}
Silicon nitride ceramics, with $\mathrm{Y}_{2} \mathrm{O}_{3}, \mathrm{Al}_{2} \mathrm{O}_{3}$ and $\mathrm{MgO}$ as sintering aids, have been sintered in a $28 \mathrm{GHz}$ microwave applicator using a number of sample insulation techniques. The sintering characteristics in terms of densification, $\alpha \rightarrow \beta$ transformation, microstructural development and power requirement were studied and compared to identical samples sintered conventionally. All of the microwave sintered materials could be sintered to near theoretical density and a full $\alpha \rightarrow \beta$ transformation obtained at temperatures around $200^{\circ} \mathrm{C}$ lower than the materials sintered conventionally. In addition, the microstructural development showed important differences, with the selective development of elongated $\beta$-grains being observed from the very early stage of transformation. Samples sintered using a powder bed insulation technique, achieved full $\alpha \rightarrow \beta$ transformation at the lowest temperature, but a tendency to thermal runaway using this method of insulation meant the samples were susceptible to cracking. Samples sintered using silicon carbide plates as a low temperature microwave absorber reached full density and onset of transformation earlier than the other materials. In addition, the maximum power requirement for these samples was around $1 / 3$ of that required for other insulation techniques, and more uniform heating meant that these samples were free from cracking.
\end{abstract}

[Received April 6, 2001; Accepted June 21, 2001]

Key-words : Silicon nitride, Microwave sintering, SiC susceptor

1. Introduction

Microwave sintering is a technology that has received considerable interest, for both oxide ${ }^{1,2)}$ and non-oxide ceramics. ${ }^{3), 4)}$ This is partly due to economical considerations, associated with lower sintering temperatures and shorter sintering times. An additional interest is due to the fact that microwave sintering is reported to be capable of producing material microstructures and properties different to those produced by conventional sintering. This phenomenon is often termed the "microwave effect." 5) The heating mechanism in microwave sintering is fundamentally different to that of conventional sintering, where heat is transferred to the surface of the sample by radiation from the furnace heating elements and then conducted through the bulk material. In microwave sintering, the material couples with the microwaves and absorbs the electromagnetic energy, transforming it into heat. This interaction between the electric field and the sample means that the heating is volumetric. ${ }^{6)}$ This method of heating the material, coupled with heat losses from the sample surface, means that the temperature profile within the material is opposite to that of conventionally fired materials, with the centre being the location of highest temperature. ${ }^{7)}$ It can be expected that the heat loss from the surface of the material can be minimised by optimal use of sample insulation. This may lead to differences in the sintering behaviour, and, from an economical point of view, in the time and power requirement to achieve fully dense ceramics.

A common problem encountered during microwave heating is the fact that many ceramics have a low dielectric loss factor and couple poorly with microwaves at low temperatures. However, the dielectric loss generally increases exponentially with temperature, and above a certain critical temperature the material will couple readily. In the case of $\mathrm{Si}_{3} \mathrm{~N}_{4}$, which is a low loss ceramic, the heating is associated with absorption by the oxide additives used to aid sintering. ${ }^{8)}$ However, this can lead to sintering problems such as thermal runaway, whereby heating of the absorbing material leads to increases in its absorbing capability and thus further increases in temperature. Such phenomena can lead to sample cracking, and one method of avoiding such problems is to use a sintering configuration that includes a material with high dielectric loss factor in order to improve microwave absorption at lower temperatures, and produce a more uniform heating. The use of such susceptors leads to hybrid sintering, which is a combination of microwave heating and conventional heating from the susceptor. Silicon carbide is probably the most common material used in this way, because of its high loss factor. Microwave sintering of $\mathrm{Si}_{3} \mathrm{~N}_{4}$, using $\mathrm{SiC}$ as a susceptor, has been carried out in a number of ways including surrounding the sample by $\mathrm{SiC}$ rods ${ }^{9)}$ and the addition of $\mathrm{SiC}$ powder to the green body. ${ }^{8}$ )

Our group has recently reported that microwave sintering of silicon nitride, using yttria, alumina and magnesia as sintering aids, results in densification and beta transformation at temperatures in the range of $200^{\circ} \mathrm{C}$ lower than identical samples sintered conventionally. ${ }^{10}$ In addition, selective heating of the grain boundary phase results in the development of elongated beta grains at a much earlier stage in the transformation process. In this work we report on the sintering behaviour of silicon nitride ceramics sintered at $28 \mathrm{GHz}$ using different insulation techniques, including the use of $\mathrm{SiC}$ plates to act as a microwave susceptor.

\section{Experimental}

\subsection{Powder preparation}

Specimens were prepared from $\alpha$ - $\mathrm{Si}_{3} \mathrm{~N}_{4}$ starting powder (Grade E-10, Ube Industries Ltd.), with oxide additives of 5.00 mass $\% \mathrm{Y}_{2} \mathrm{O}_{3}$ (RU-P, Shin-Etsu Rare Earth Ltd.), 3.58 mass $\% \mathrm{Al}_{2} \mathrm{O}_{3}$ (AKP-50, Sumitomo Chemical Ltd.) and 
1.42 mass\% $\mathrm{MgO}$ (1000A, Ube Industries Ltd.). The relative amounts of $\mathrm{Al}_{2} \mathrm{O}_{3}$ and $\mathrm{MgO}$ were chosen so as to give an overall composition of $5 \%$ by weight of the spinel, $\mathrm{MgAl}_{2} \mathrm{O}_{4}$. The powders were mixed and planetary milled in methanol, before being dried by evaporation and vacuum oven heating. The dried powders were sieved through a $250 \mu \mathrm{m}$ mesh and uniaxially pressed under a pressure of $7.6 \mathrm{MPa}$ before being cold isostatically pressed under $500 \mathrm{MPa}$. The samples for microwave sintering were pressed into rectangular samples $(47 \mathrm{~mm} \times 42 \mathrm{~mm} \times 5 \mathrm{~mm})$, while the samples for conventional sintering were in the form of pellets $(\phi 15 \mathrm{~mm} \times 5$ $\mathrm{mm})$.

\subsection{Microwave sintering}

The pressed samples were sintered in a nitrogen atmosphere of $0.1 \mathrm{MPa}$, in an applicator fed by a $28 \mathrm{GHz} \mathrm{Gy}-$ rotron source (FDS-10-i28, Fuji Dempa Kogyo Ltd.) as reported previously. ${ }^{11)}$ The insulation methods for these samples are shown in Fig. 1. In the first configuration, Fig. 1a), the samples were placed on a boron nitride plate and located inside the chamber surrounded by porous $\mathrm{Al}_{2} \mathrm{O}_{3}$. The samples sintered in this way are hereafter referred to as SN-A. The second configuration, Fig. 1b), involved locating the sample in a $50: 50 \mathrm{Si}_{3} \mathrm{~N}_{4}: \mathrm{BN}$ powder bed within a doubled walled boron nitride crucible arrangement, and again surrounding by $\mathrm{Al}_{2} \mathrm{O}_{3}$, referred to as $\mathrm{SN}-\mathrm{PB}$. The final experimental set-up, Fig. 1c), was similar to the second but with the sample sandwiched between two silicon carbide plates which absorb the microwaves at low temperatures and act as a heat susceptor. ${ }^{12)}$ These samples are referred to hereafter as SN-SC.

Sintering was carried out at temperatures ranging from 1100 to $1750^{\circ} \mathrm{C}$ with $1 \mathrm{~h}$ holding at temperature. The heating rate was approximately $10^{\circ} \mathrm{C} \mathrm{min}-1$, and following the holding period the samples were allowed to cool in the applicator at an average cooling rate of $20^{\circ} \mathrm{C} \mathrm{min}^{-1}$. The accuracy of temperature measurement is a common problem encountered during microwave sintering. In the present work, in order to minimise errors, the following steps were taken. The temperature was monitored by a W-Re thermocouple with a molybdenum sheath. The use of metal sheaths is thought to reduce thermocouple/microwave interactions. The thermocouple was embedded in the centre of the sample by drilling a hole in the green body. In this way the bulk temperature was measured at the hottest part of the sample. Prior to use, all thermocouples were subjected to X-ray ex- amination in order to determine the distance from the sheath tip to actual thermocouple. Only those with a thermocouple to tip separation of less than $5 \mathrm{~mm}$ were used in the experiments, ensuring that the thermocouple was indeed inside the sample.

\subsection{Conventional sintering}

The samples were buried in a $50: 50 \mathrm{BN}: \mathrm{Si}_{3} \mathrm{~N}_{4}$ powder bed and located inside a resistance heating furnace inside a double walled crucible arrangement. The inner crucible was boron nitricle and the outer was of graphite. The furnace was heated to the desired temperature at a rate of $10^{\circ} \mathrm{C}$ $\min ^{-1}$ in a $0.1 \mathrm{MPa}$ nitrogen gas atmosphere. The holding temperatures for these samples ranged from 1450 to $1750^{\circ} \mathrm{C}$ and the temperature was monitored at the wall of the crucible by optical pyrometer, calibrated to the actual temperature within the crucible.

\subsection{Characterisation}

Sintered specimens for microstructural analysis were polished through successive grades of silicon carbide and finished with $0.5 \mu \mathrm{m}$ diamond slurry. Plasma etching was carried out in $\mathrm{CF}_{4}$ (Plasma reactor PR-41, Yamato Science Co., Ltd.). The etched samples were gold coated for electron conductivity and microstructural characterisation was carried out by scanning electron microscopy, (SEM; JSM-6340, JEOL Ltd.) and quantitative image analysis. Phase analysis was carried out by X-ray diffraction (Model $\mathrm{RAD}-\mathrm{RB}$, Rigaku), and the relative amounts of $\alpha$ and $\beta$-Si ${ }_{3} \mathrm{~N}_{4}$ were determined following the method reported by Gazzara and Messier. ${ }^{13)}$ Bulk density was measured by the Archimedes method in distilled water.

\section{Results and discussion}

\subsection{Phase transformation and densification}

The measured density of the samples is shown in Fig. 2. For the conventionally sintered samples the density at the lowest sintering temperature of $1450^{\circ} \mathrm{C}$ was around $70 \%$ of theoretical density (green body density $\approx 55 \%$ ), and this increased to over $97 \%$ theoretical density at $1700^{\circ} \mathrm{C}$.

The microwave-sintered specimens showed improved densification at lower temperatures when compared to the conventional samples. The density of the SN-SC samples had reached over $97 \%$ of theoretical density at a sintering temperature of $1300^{\circ} \mathrm{C}$, whilst this density was achieved at $1450^{\circ} \mathrm{C}$ in the SN-A and SN-PB materials.

Figure 3 shows the $\alpha \rightarrow \beta$ transformation characteristics of

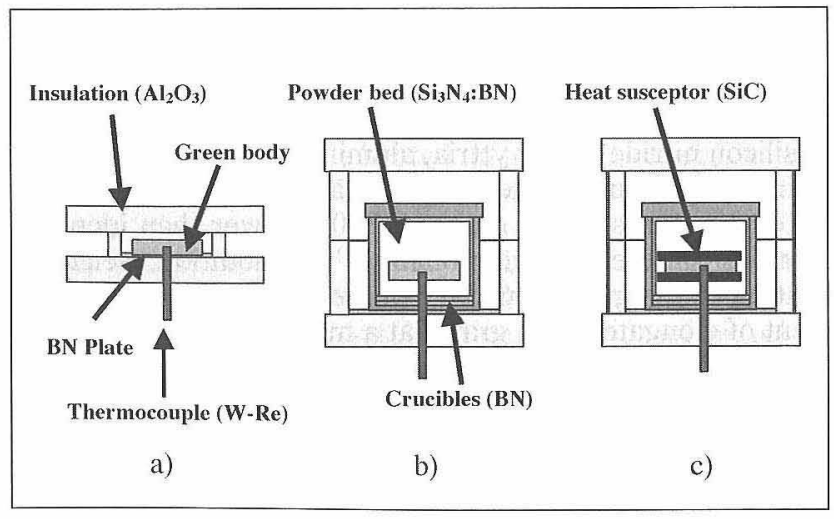

Fig. 1. Specimen insulation techniques. In the first set up the sample was simply surrounded by porous alumina $(\mathrm{SN}-\mathrm{A})$. In the second configuration the sample was located in a $\mathrm{Si}_{3} \mathrm{~N}_{4}$ : BN powder bed within $\mathrm{BN}$ crucibles (SN-PB). The final configuration was the same as the second, with the addition of two $\mathrm{SiC}$ plates to absorb microwaves at low temperature (SN-SC).

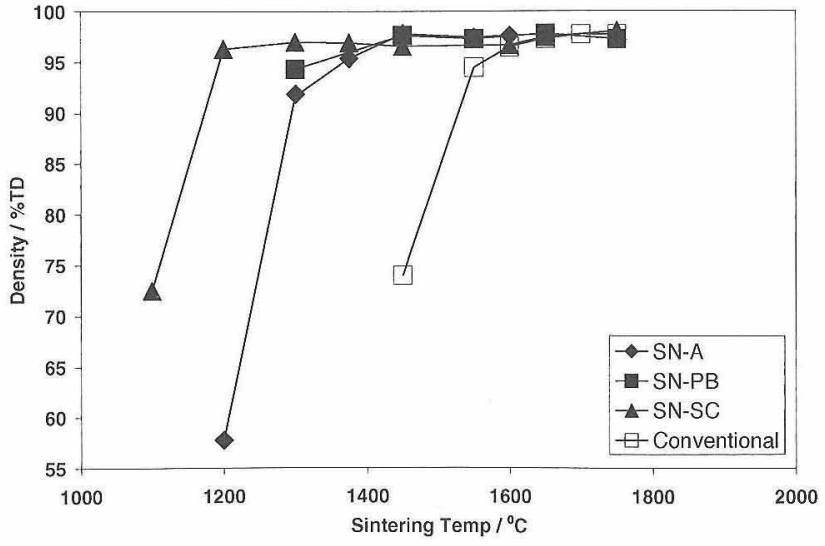

Fig. 2. Densification curves for all the specimens following $1 \mathrm{~h}$ at sintering temperature. All microwave sintered specimens exhibited enhanced densification when compared to the conventionally sintered material. The samples sintered with the use of $\mathrm{SiC}$ plates show full densification at the lowest temperature. 


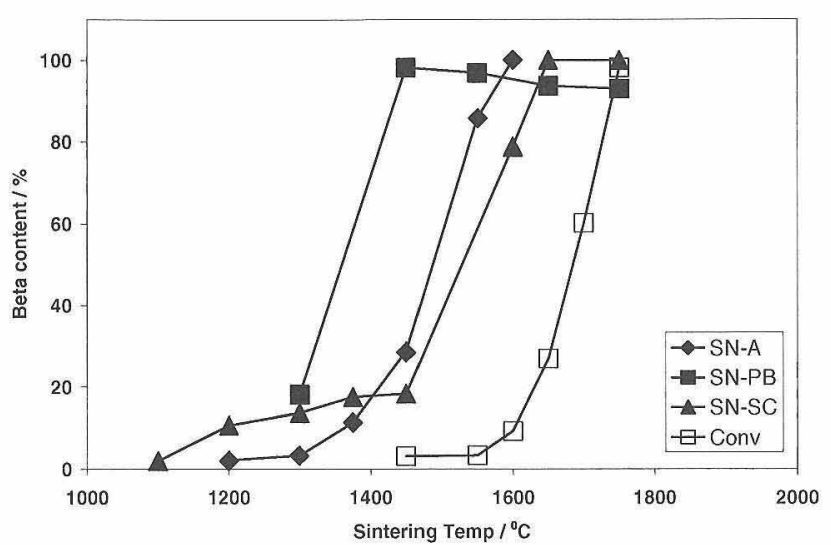

Fig. 3. $\alpha \rightarrow \beta$ transformation curves for the sintered bodies after $1 \mathrm{~h}$ sintering. Again all microwave sintered specimens achieve full $\beta$ transformation at temperatures in the order of $200^{\circ} \mathrm{C}$ lower than those sintered conventionally. Amongst the microwave sintered samples, the SN-PB material showed full transformation at the lowest temperature.

both the microwave and conventionally sintered specimens. In the conventionally sintered material, phase transformation had begun following $1 \mathrm{~h}$ sintering at $1600^{\circ} \mathrm{C}$, and was fully complete following $1 \mathrm{~h}$ sintering at $1750^{\circ} \mathrm{C}$. For the microwave sintered samples, transformation was evident at a sintering temperature of 1200,1300 and $1375^{\circ} \mathrm{C}$ for the SN-SC, SN-PB and samples SN-A materials respectively. The SN-PB material had attained full transformation by $1450^{\circ} \mathrm{C}$, and in the SN-A and SN-SC materials, full $\beta$ was achieved at temperatures of 1600 and $1650^{\circ} \mathrm{C}$, respectively.

The microwave sintered samples all showed improved densification and $\alpha \rightarrow \beta$ transformation when compared to the conventionally sintered materials. Near theoretical density was obtained at temperatures around $200^{\circ} \mathrm{C}$ lower than that required for the conventional material, and full $\beta-\mathrm{Si}_{3} \mathrm{~N}_{4}$ was achieved at a temperature at least $100^{\circ} \mathrm{C}$ lower than the conventionally sintered material, depending on insulation configuration. Kim et al. ${ }^{14}$ ) reported similar reductions in temperature for silicon nitride sintered at $2.45 \mathrm{GHz}$ with $\mathrm{Y}_{2} \mathrm{O}_{3}$ and $\mathrm{Al}_{2} \mathrm{O}_{3}$ as sintering aids. There is a growing body of evidence to support the claims that use of microwaves leads to reductions in sintering temperature, as observed in this work, but there is the ever present question as to the accuracy of temperature measurement during microwave sintering. This issue is certainly a non-trivial problem, and the issue, therefore, is whether microwave enhanced effects are to be described simply in terms of the reduction in sintering temperature which leads to similar microstructures, $\Delta T$, as suggested by Boch and Lequeux, ${ }^{15)}$ or whether a difference can be observed in the densification mechanism between conventionally sintered and microwave sintered samples.

3.2 Microstructural development

In addition to a reduction in sintering temperatures, the microstructural development in the conventionally and microwave sintered materials at the same stage of sintering, that is, at over $95 \%$ theoretical density and comparable stage in the transformation process, were significantly different. The microstructures of the sintered bodies during the $\alpha \rightarrow \beta$ transformation are shown in Fig. 4. All of the samples shown in this figure had a $\beta-\mathrm{Si}_{3} \mathrm{~N}_{4}$ content of between 20 and $30 \%$. The microstructure of the conventionally sintered material consisted of uniform, equiaxed grains. However, in the microwave sintered samples the selective development of elongated grains could be observed. From the characteristic feature of these grains, and the X-ray analysis shown
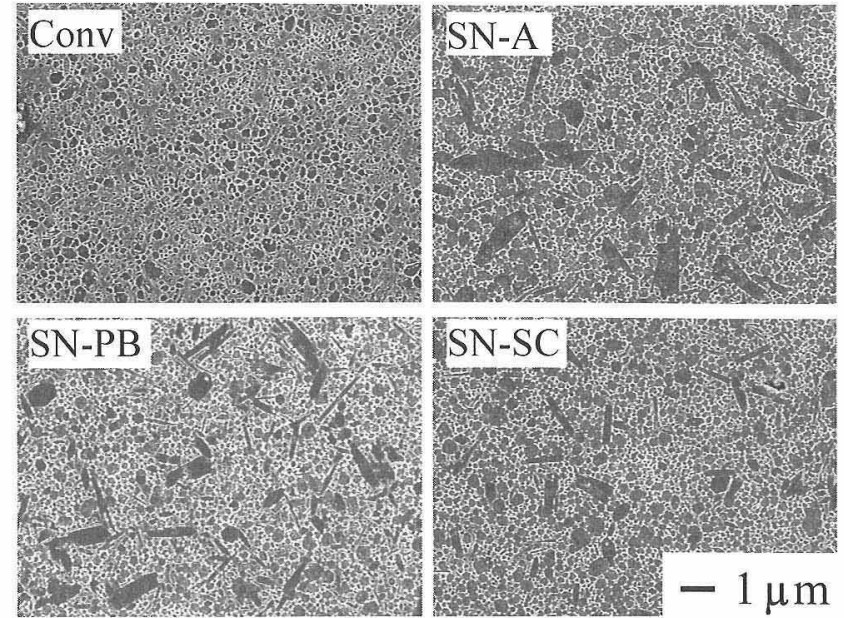

Fig. 4. SEM micrographs of the sintered bodies during the $\alpha \rightarrow \beta$ transformation. In all of these samples, the $\beta-\mathrm{Si}_{3} \mathrm{~N}_{4}$ content, as determined by X-ray diffraction analysis, was between 20 and $30 \%$. All of the microwave sintered samples show the development of elongated grains.

in Fig. 3, it is apparent that these elongated grains are $\beta$ $\mathrm{Si}_{3} \mathrm{~N}_{4}$. Such grains were observed in all of the microwave sintered materials at $\beta$ contents as low as $10 \%$, and their number increased with sintering temperature. In contrast, no grain development was observed in the conventionally sintered material until the transformation was almost complete. The fact that this grain development was also observed when sintering with the susceptor, is evidence that the use of this technique really is a hybrid technique and not simply conventional heating of the sample from the $\mathrm{SiC}$ plates.

Plucknett and Wilkinson ${ }^{16)}$ reported that microwave sintering of silicon nitride resulted in microstructures that were significantly refined in comparison with conventionally sintered material. These authors suggested that this may be due to the selective heating of the oxide sintering additives resulting in a higher $\beta$ nucleation rate caused by a temperature gradient driven dissolution process. However most researchers report enhanced grain growth for microwave sintered $\left.\left.\mathrm{Si}_{3} \mathrm{~N}_{4} 4\right), 87,14\right), 17$ ) and in this work it is obvious that, particularly in the early stages of the transformation process, microwave sintering leads to selective development of $\beta$ grains. As reported in a recent paper, ${ }^{10)}$ the selective heating of the grain boundary phase could actually lead to fewer nucleation sites due to dissolution of pre-existing $\beta$ nuclei. Dressler et al. ${ }^{18)}$ have described how small $\beta$ particles can dissolve during the solution precipitation process due to changes in the equilibrium concentrations of $\mathrm{Si}_{3} \mathrm{~N}_{4}$ in the liquid phase at the particle surface, for example due to the growth of an adjacent larger crystal. Higher nitrogen solubility in the glass phase shifts the critical size, below which $\beta$ particles dissolve, to higher values, ${ }^{19)}$ and localised heating of the grain boundary phase, during microwave sintering, may then also lead to the dissolution of $\beta$ particles, since the solubility of nitrogen in the glass increases with temperature. ${ }^{20)}$

Once the transformation was complete however, the microstructures of all the materials were apparently similar. Figure 5 shows the microstructures of the samples at the lowest temperature at which full transformation to $\beta-\mathrm{Si}_{3} \mathrm{~N}_{4}$ had been achieved. In this figure the microstructure of the conventionally sintered materials is much more akin to those of the microwave sintered materials, although this 

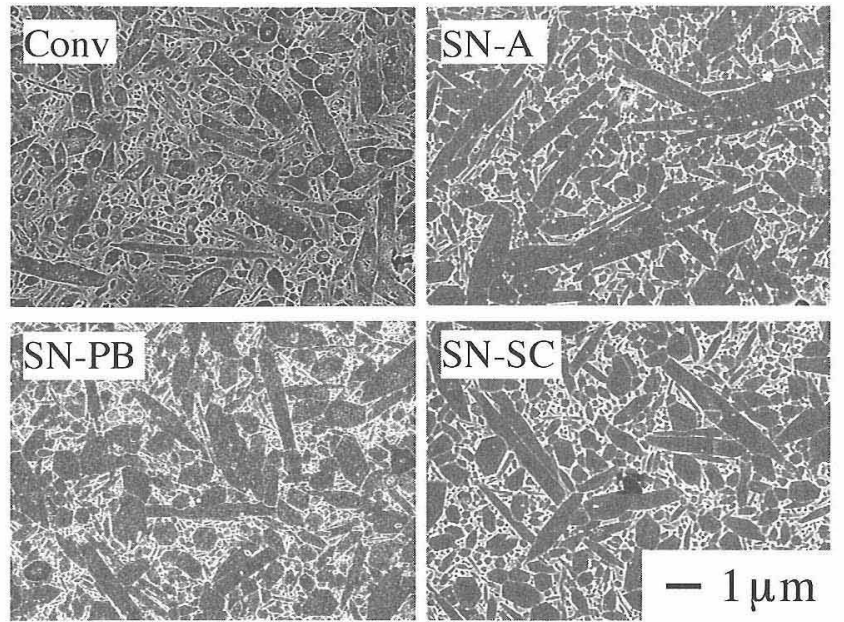

Fig. 5. Microstructures of the sintered bodies at the end of the transformation process. The microstructures are similar in terms of grain size and size distribution, although more grain impingement is observed in the microwave sintered materials.

may be due to the impingement of adjacent grains, restricting further grain growth in the case of the latter.

3.3 Power requirement

The power required to heat the microwave sintered bodies to a temperature of $1450^{\circ} \mathrm{C}$ is shown in Fig. 6. For all the samples, there was a reduction in power requirement at a temperature of around $900^{\circ} \mathrm{C}$, thought to be associated with the fact that microwaves couple better with silicon nitride, due to the increasing loss tangent, at higher temperatures. The SN-A and SN-PB samples required a maximum power between 3 and 4 times that of the SN-SC. In addition, these two materials showed a dramatic decrease in power at a temperature of approximately $1250^{\circ} \mathrm{C}$, thought to be connected with the formation of the liquid phase. In addition to these decreases, the power requirement curves show general fluctuations due to the automated feedback system used to control the heating rate. Slight variations in actual heating rate produce a response in the power input, in order to maintain the set rate. This fluctuation is more pronounced for the SN-SC samples, as can be seen in Fig. 6. This is a result of the improved microwave absorption in these samples, which means that heating of the sample occurs more readily than with the other configurations, and in order to maintain the same heating rate, the power is constantly undergoing adjustment.

Amongst the microwave sintered materials, the samples sintered using the $\mathrm{SiC}$ plate configuration (SN-SC) initially showed the best sintering characteristics, with densification and the onset of the $\beta$ transformation occurring earlier than the other materials. This is thought to be due to the improved absorption of microwaves at the lower temperatures by the $\mathrm{SiC}$ plates. In this case the heating is more like a hybrid heating technique, with reduced heat losses from the surface of the $\mathrm{Si}_{3} \mathrm{~N}_{4}$ and a conventional radiative type heating contribution from the susceptor itself.

When sintering using the powder bed technique, in particular, samples were susceptible to cracking, especially when attempting to sinter at lower temperatures. The reason for this may be associated with dramatic decrease in power seen for this material at temperatures of around $1250^{\circ} \mathrm{C}$. This decrease in power requirement is thought to be associated with improved microwave absorption due to the introduction of the liquid phase. If the liquid phase occurs selectively in the material due to differences in micro-

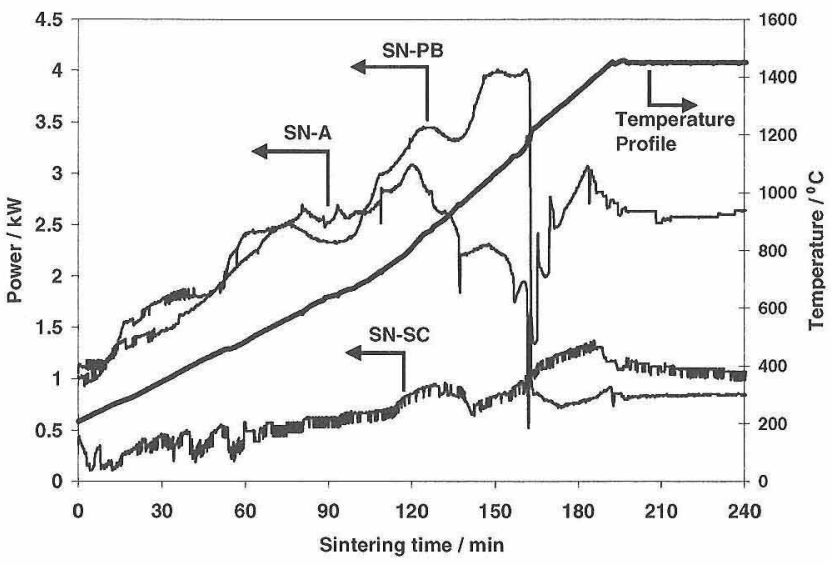

Fig. 6. Power requirement for sintering of the samples at $1450^{\circ} \mathrm{C}$. The SN-A and SN-PB samples required a much higher power than the SN-SC to maintain the same heating rate, due to the absorption of microwaves by the susceptor in the latter. In addition, these two materials show a dramatic decrease in power requirement at around $1250^{\circ} \mathrm{C}$, thought to be associated with the formation of the eutectic phase.

wave absorption in different locations, possibly due to the distribution of the oxide additives, or, as is more likely, due to inhomogeneous distribution of the electromagnetic field, then the shrinkage characteristics of the material may become non-uniform. This becomes significantly important at lower temperatures where there is the possibility that areas of the green body are below the liquidus temperature and differential shrinkage leads to the possibility of cracking. This phenomenon can be exacerbated by the fact the selectively heated areas show improved microwave absorption, thus increasing the temperature further and leading to the possibility of thermal runaway. Zhao et al. ${ }^{21)}$ suggested that the use of a $\mathrm{SiC}$ susceptor can have a compensating effect on such an inhomogeneous electromagnetic field since the absorption takes place within the susceptor leading to less penetration of the microwaves. This method of heating leads to a more uniform distribution of the electromagnetic field and hence the heating within the sample is more uniform, consequently improving sintering reproducibility.

\section{Conclusions}

The microwave samples produced in this work all showed improved sintering behaviour in comparison to the conventionally sintered materials. Full densification was achieved at temperatures around $200^{\circ} \mathrm{C}$ lower than the samples sintered conventionally, and full transformation to $\beta-\mathrm{Si}_{3} \mathrm{~N}_{4}$ occurred at temperatures over $100^{\circ} \mathrm{C}$ lower. In the microwave sintered samples, the selective development of elongated $\beta$ grains was observed from the very early stages of transformation.

Amongst the microwave sintered samples, the ones produced with the $\mathrm{SiC}$ plate insulation configuration showed densification and transformation at an earlier stage, due to the contribution to sample heating provided by the absorption of microwaves at low temperatures, and reduced surface heat loss. As a consequence of this type of heating, these samples could be sintered to full density with power levels of between 33 and $50 \%$ of that required for the other insulating techniques. In addition, the uniform heating of the sample with this insulation method meant that sample integrity and reproducibility was greatly improved over the other techniques. 
Acknowledgements This work has been carried out under the STA Fellowship Program managed by the Japan Science and Technology Corporation (JST) in co-operation with the Japan International Science and Technology Exchange Center (JISTEC). Special thanks are due to Dr. M. E. Brito of Synergy Materials Research Center, AIST, for useful discussions relating to this work.

\section{References}

1) Wroe, R. and Rowley, A. T., J. Mater. Sci., 31, 2019-26 (1996).

2) Janney, M. A. and Kimrey, H. D., "Ceramic Transactions Vol. 1, b, Ceramic Powder Science II,” Ed. by Messing, G. L., Fuller, E. R. and Hausner, H., Am. Ceram. Soc., Westerville, $\mathrm{OH}$ (1988) pp. 919-24.

3) Katz, J. D., Annu. Rev. Mater. Sci., 22, 153-70 (1992).

4) Kim, Y. C., Kim, C. H. and Kim, D. K., J. Eur. Ceram. Soc., 17, 1625-30 (1997)

5) Clark, D. E., Folz, D. C. and West, J. K., Mater. Sci. Eng., A287, 153-58 (2000).

6) Sutton, W. H., Am. Ceram. Soc. Bull., 68, 376-86 (1989).

7) Birnboim, A. and Carmel, Y., J. Am. Ceram. Soc., 82, 3024-30 (1999).

8) Tiegs, T. N., Kiggans, J. O. and Kimrey, H. D., Ceram. Eng. Sci. Proc., 12, 1981-92 (1991).

9) $\mathrm{Xu}$, G., Zhuang, H., Li, W. and Wu, F., J. Eur. Ceram. Soc., 17, 977-81 (1997).
10) Jones, M. I., Valecillos, M.-C., Hirao, K. and Toriyama, M., submitted to J. Am. Ceram. Soc.

11) Valecillos, M.-C., Hirota, M., Brito, M. E., Hirao, K. and Toriyama, M., J. Ceram. Soc. Japan, 106, 1162-66 (1998).

12) Lasri, J., Ramesh, P. D. and Schachter, L., J. Am. Ceram. Soc., 83, 1465-68 (2000).

13) Gazzara, C. P. and Messier, D. R., Am. Ceram. Soc. Bull., 56, 777-80 (1977).

14) Kim, Y. C., Koh, S. C., Kim, D. Y. and Kim, C. H., "Microwaves: Theory and Application in Materials Processing III," Ed. by Clark, D. E., Folz, D. C., Oda, S. J. and Silberglitt, R., Am. Ceram. Soc., Westerville, OH (1995) pp. 415-22.

15) Boch, Ph. And Lequeux, N., Solid State Ionics, 101-103, 1229-33 (1997).

16) Plucknett, K. P. and Wilkinson, D. S., Mater. Res. Soc. Symp. Proc., 287, 289-94 (1993).

17) Hirota, M., Brito, M. E., Hirao, K., Watari, K., Toriyama, M. and Nagaoka, T., Mater. Res. Soc. Symp. Proc., 430, 441-45 (1996).

18) Dressler, W., Kleebe, H.-J., Hoffmann, M. J., Rühle, M. and Petzow, G., J. Eur. Ceram. Soc., 16, 3-14 (1996).

19) Kitayama, M., Hirao, K., Toriyama, M. and Kanzaki, S., J. Ceram. Soc. Japan, 107, 930-34 (1999).

20) Kleebe, H.-J., J. Ceram. Soc. Japan, 105, 453-75 (1997).

21) Zhao, C., Vleugels, J., Groffils, C., Luypaert, P. J. and Van Der Biest,O., Acta. Mater., 48, 3795-801 (2000). 